\title{
Peripheral blood saturation and pulse rate during swallowing in patients with oral cavity neoplasm and after its excision
}

\section{Nasycenie krwi obwodowej tlenem i tętno podczas przełykania u pacjentów z nowotworem jamy ustnej oraz po jego wycięciu}

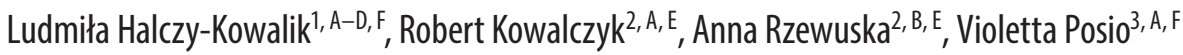 \\ 1 Independent Laboratory of Postoperative Rehabilitation in Maxillofacial Surgery, Pomeranian Medical University of Szczecin, Szczecin, Poland \\ 2 Clinic of Maxillofacial Surgery, Pomeranian Medical University of Szczecin, Szczecin, Poland \\ ${ }^{3}$ Department of Imaging Diagnostics and Interventional Radiology, Pomeranian Medical University of Szczecin, Szzzecin, Poland \\ A - research concept and design; $\mathrm{B}$ - collection and/or assembly of data; $\mathrm{C}$ - data analysis and interpretation; \\ $D$ - writing the article; $E$ - critical revision of the article; $F$ - final approval of article
}

Address for correspondence

Ludmiła Halczy-Kowalik

E-mail: sprpchst@pum.edu.pl

Funding sources

none declared

Conflict of interest

none declared

Acknowledgment

We are very grateful to Barbara Zaborek, PhD for her help in thorough statistical assessment of the results.

Received on August 24, 2016 Revised on 0ctober 11, 2016 Accepted on 0ctober 14, 2016

DOI

$10.17219 / \mathrm{dmp} / 65831$

Copyright

@ 2017 by Wroclaw Medical University

and Polish Dental Society

This is an article distributed under the terms of the

Creative Commons Attribution Non-Commercial License

(http://creativecommons.org/licenses/by-nc-nd/4.0/)

\begin{abstract}
Background. Breath holding during swallowing enables safe transport of bolus from the oral cavity to the esophagus without threat of aspiration into the lower airways. Inter-deglutition apnea elongation needed for the performance of several swallows supporting non-efficient lower pharynx emptying in the patients after oral cavity neoplasm excision, may be the cause of the peripheral blood saturation decrease
\end{abstract}

Objectives. The aim of the study was to assess peripheral blood saturation during swallowing in patients with oral cavity neoplasm and after its excision.

Material and methods. One hundred fifty-six patients with oral cavity neoplasm were scheduled for surgical treatment. Pulse oximetry was performed before surgery, and 2 and 4 weeks post-surgically. Video fluoroscopic swallowing examination was performed 2 and 4 weeks post-surgically, simultaneously with pulse oximetry.

Results. After neoplasm excision, desaturation was indicated by time percentage of saturation lower than 95\% increase and pulse rate acceleration. We recorded improved saturation 4 weeks after surgery and after the rehabilitation of swallowing; there was an increase in the lowest saturation value and a decrease in time percentage of saturation lower than $95 \%$. Post-deglutition retention correlated most with the saturation. Time percentage of saturation lower than $95 \%$ for post-deglutition retention was a sensitive test in $82 \%$, and a specific test in $70 \%$

Conclusions. The course of act swallowing improves in patients subjected to swallowing rehabilitation after oral cavity neoplasm excision as time passes by after surgery. Desaturation during swallowing in patients after oral cavity excision improves as time passes by in patients subjected to swallowing rehabilitation. Post-deglutition retention indicating that inefficient swallowing and aspiration threat are present is a feature of disturbed swallowing act which correlates the most with desaturation, especially with time percentage of saturation lower than $95 \%$.

Key words: deglutition disorders, saturation, oral cancer excision, post-deglutition retention

Słowa kluczowe: zaburzenia połykania, nasycenie tlenem, wycięcie raka jamy ustnej, zaleganie popołknięciowe 
Breathing, one of the most important life functions, may be temporarily restricted during phonation and swallowing. In proper deglutition the larynx closure lasts from 0.4 to $0.6 \mathrm{~s}$ and generally does not lead to desaturation ${ }^{1}$, except for in older patients. ${ }^{2-5}$

Oral neoplasm excision changes the anatomy and functions of organs responsible for swallowing, speech creation and breathing. A decrease in the organ mass, movement limitation and limited sensory efficiency disturb swallowing by preventing patients from feeding themselves orally. Reconstruction of excised structures, even if performed in one-step surgical procedure, does not guarantee the recovery of efficient swallowing and eligible speech $^{6}$. Teaching patients saliva swallowing, especially long breath-holding, creates a new pattern of swallowing. Such an elongated, mid-swallowing apnea can lead to reduced peripheral blood saturation. The level of desaturation and its duration may indicate the necessity of some changes in planned swallowing reeducation.

The aim of this study was to assess saturation as one of the significant conditions in swallowing rehabilitation after oral cavity neoplasm excision.

\section{Material and methods}

One hundred fifty-six patients were treated surgically due to oral cavity neoplasm: 110 men aged 22-86 years (mean age 56.7), and 46 women aged $37-77$ years (mean age 57.35). The criterion of inclusion into the study group was histopathologically diagnosed primary squamous cell carcinoma of its origins in oral cavity mucosa. Patients with cancer recurrence or with respiratory, heart or blood vessels diseases were not included into the study group. The patients were not diagnosed nor treated due to breathing or swallowing disturbances before surgery. Neoplasm, the range of excision, and reconstruction data are presented in Table 1.

Pulse oximetry of the peripheral blood saturation was performed in patients with oral cavity cancer before surgery, and 2 and 4 weeks post-surgically. All patients were advised to learn how to swallow their saliva freely; in the early post-surgical period they were asked for planned saliva swallowing every hour. Two weeks after surgery, patients considered their saliva swallowing as effortless.

Before surgery, saturation assessment was performed in the early hours, between 9 and 10 a.m. For the first $15 \mathrm{~min}$, peripheral blood saturation was examined in patients during their usual daily activities; a further part of examination was performed as the patient drank $25 \mathrm{~mL}$ of still mineral water; another 15 min of the examination was performed during patients' usual daily activities. Two and 4 weeks after surgery, saturation assessment began 15 min before video fluoroscopic swallowing examination, continued during the examination, and finished 15 min after video fluoroscopic swallowing examination.
The index finger of a patient's right hand was placed in the pulse oximeter sensor. The measurement was performed with the use of Pulse Oximeter Palmsat ${ }^{\circledR} 2500$ (Plymouth, USA) and based on the assessment of the red and sub-red light absorbance by the red blood cells flowing through a blood vessel. The result was diversified accordingly with oxyhemoglobin content in the red blood cell. The changes in the light absorbance produced by the blood pulse in a blood vessel were used to assess the pulse rate. The recording of examination was stored in the Pulse Oximeter device memory, and then entered into a database created by the manufacturer. The database was able to gather any number of examination results. We chose 5 scores from the gathered data: basal saturation, minimum saturation, the average number of pulse rate per min, the minimum number of pulse rate per min, and the percentage of time period with saturation lower than $95 \%$.

Saturation and pulse rate were examined before surgery in 75 patients, 2 weeks post-surgically in 133 patients, and 4 weeks post-surgically in 66 patients. Saturation assessment in the group of 156 patients was possible due to the following reasons: 1 ) only 75 patients spent the night before surgery in the hospital; 2) 23 patients with oral nutrition left hospital no later than 2 weeks after surgery; 3) 90 patients decided for oral nutrition no later than 4 weeks after surgery.

Two weeks after surgery, 133 patients fed with nasogastric tube who did not start oral feeding, were subjected to the swallowing rehabilitation. It was preceded by video fluoroscopic examination performed as in Dodds, Logeman and Steward's research. ${ }^{7,8}$ The examination showed aspiration, leakage into the larynx vestibule, post-deglutition retention in the lower pharynx, and oral cavity outflow apart from jaws occlusion. The examination verified the compensatory mechanisms applied spontaneously by patients during swallowing, enabled checking the effectiveness of new maneuvers recommended during the examination such as changing the posture, apnea elongation, epiglottal and supra-epiglottal swallowing. Each patient was provided with their swallowing recording with the information on the causes of swallowing disturbances and rehabilitation recommendations. Peripheral blood saturation assessment performed during video fluoroscopic swallowing examination facilitated the observation and recording of saturation of which parameters were changing during swallowing.

Four weeks after surgery, 66 patients still fed through nasogastric tube were subjected to video fluoroscopic examination of swallowing. The examination enabled us to check the effectiveness of previous swallowing rehabilitation and possible changes which could be applied in the further course of rehabilitation. The changes were discussed with every patient during watching the recorded swallowing act. The assessment of saturation completed the observation made during the examination 3 . 
Table 1. Characteristic of squamous oral cavity cancer; treatment

\begin{tabular}{|c|c|c|c|c|}
\hline \multicolumn{2}{|c|}{$\begin{array}{l}\text { Tumor localization, clinical advancement, } \\
\text { treatment }\end{array}$} & \multicolumn{3}{|c|}{ Number of patients } \\
\hline $\begin{array}{l}\text { Tumor } \\
\text { localization }\end{array}$ & $\begin{array}{l}\text { tongue } \\
\text { tongue root } \\
\text { floor of the mouth } \\
\text { mandible, lower gingiva } \\
\text { retromolar trigone } \\
\text { others }\end{array}$ & & $\begin{array}{l}48 \\
16 \\
42 \\
21 \\
19 \\
10\end{array}$ & \\
\hline $\begin{array}{l}\text { Clinical } \\
\text { advancement }\end{array}$ & $\begin{array}{l}\text { I } \\
\text { II } \\
\text { III } \\
\text { IV }\end{array}$ & & $\begin{array}{l}32 \\
40 \\
58 \\
26\end{array}$ & \\
\hline Treatment & $\begin{array}{l}\text { surgical (only) } \\
\text { surgical + radiotherapy } \\
\text { surgical + radiotherapy } \\
\text { + chemotherapy }\end{array}$ & & $\begin{array}{l}28 \\
44 \\
84\end{array}$ & \\
\hline $\begin{array}{l}\text { The range of } \\
\text { oral cavity } \\
\text { tissues excision }\end{array}$ & $\begin{array}{l}\text { 1) front of part of tongue, } \\
\text { floor of mouth, mandible } \\
\text { 2) lateral part of tongue, } \\
\text { floor of mouth, mandible } \\
\text { 3) a half of mandible and } \\
\text { half of tongue along } \\
\text { 4) together as in } 1 \text { and } \\
3 \text { group } \\
\text { 5) whole tongue } \\
\text { 6) a half of the tongue } \\
\text { along } \\
\text { 7) ramus of mandible, } \\
\text { lateral pharynx part, root } \\
\text { of tongue }\end{array}$ & $\begin{array}{l}23 \\
58 \\
7\end{array}$ & $\begin{array}{c}\text { recor } \\
\text { yes } \\
14 \\
24 \\
5\end{array}$ & $\begin{array}{l}\text { Iction } \\
\text { no } \\
9 \\
34 \\
2 \\
0 \\
0 \\
7 \\
35\end{array}$ \\
\hline
\end{tabular}

\section{Statistical methods}

Pulse oximeter recordings were gathered in a database, and after compiling them with the parameters of features of the disturbed swallowing act, analyzed with the use of:

- Student's t-test of the dependent variables or the Wilcoxon test of 2 related samples from the same patient in 2 examinations.

- Analysis of variance (ANOVA) or Kruskal-Wallis test.

- Student's t-test for independent variables or the MannWhitney U test.

- The Kolmogorov-Smirnov test.

- Spearman's rank correlation test.

The results were described with the use of the correlation coefficient $\mathrm{r}$ and $\mathrm{p}$ value. $\mathrm{P}<0.05$ was considered as statistically significant in all of the aforementioned tests.

\section{Results}

\section{Pulse oximetry assessment}

In the study group of 156 patients, there were no statistically significant correlations between peripheral blood saturation and the patient's age or gender. However, we reported statistically significant differences $(\mathrm{p}=0.0001)$ in the rate of the slowest pulse. In post-surgical examinations, the rate was on average 10 beats per min higher in women than in men.

During examination 1, before the surgery performed on 73 patients, we reported that the neoplasm localization in the front part of the oral cavity was statistically significantly correlated ( $\mathrm{p}=0.0053$ ) with the lowest peripheral blood saturation during swallowing. Neoplasm infiltrating the tongue was statistically significantly correlated ( $\mathrm{p}=0.0315$ ) with longer lasting time of peripheral blood saturation lower than 95\% during swallowing compared to patients with other localizations of the neoplasm. Table 2 presents the medium values of saturation and pulse rate measurements from examinations performed in patients with oral cavity neoplasm, and after 2 and 4 weeks postsurgically.

In examination 2, performed on 133 patients 2 weeks after surgery, we reported the percentage elongation of saturation time lower than 95\% ( $p=0.0374$ ), as well as a statistically significant increase in the pulse rate ( $p=0.0075)$ in comparison with the pre-surgical examination recorded. Moreover, we observed a minor and statistically insignificant decrease in basal and minimum saturation.

In the examination 3 , performed on 66 patients 4 weeks after surgery, we reported a statistically significant improvement in measurements concerning the saturation in comparison with the examination 1 ; the lowest saturation increased ( $p=0.0027)$, and the percentage of saturation time was lower than $95 \%$ decrease $(\mathrm{p}=0.0047)$.

\section{Video fluoroscopic examination}

In the examination conducted 2 weeks after surgery we reported a disturbance of bolus formation in the oral cavity, inefficient oral bolus transport, premature bolus entry in the pharynx, post-deglutition retention in the oral cavity and pharynx, ineffective lower airways closure during swallowing, leakage into the laryngeal vestibule, and aspiration. Table 3 presents the chosen features of disturbed act of swallowing recorded in patients after 2 and 4 weeks following oral cavity neoplasm excision. The number of patients with disturbances in examination 3 was lower in comparison to examination 2.

The most serious swallowing disturbance, aspiration, did not correlate in a statistically significant manner with the age or gender of patients. Aspiration correlated statistically significantly with the range of tumor excision, i.e., it was recorded more often after the excision of more than a half of the movable part of the tongue $(p=0.00585)-$ group 4, and after the excision of the root of the tongue $(p=0.00785)-$ group 7 . Aspiration correlated with postdeglutition retention in the lower larynx ( $p=0.00001)$. The number of patients with aspiration decreased from 10 to 7 during a 4-week observation. 
Table 2. Chosen values of saturation measured during swallowing in patients after oral cavity neoplasm excision

\begin{tabular}{|c|c|c|c|c|c|c|c|}
\hline Variable & Examination & Compared & $\mathrm{p}$ & Mean 1 & Mean 2 & N1 & N2 \\
\hline \multirow[t]{3}{*}{ Basal $\mathrm{O}_{2}$} & 1 & 2 & 0.1187 & 96.21 & 95.74 & 73 & 133 \\
\hline & 1 & 3 & 0.1719 & 96.21 & 95.77 & 73 & 66 \\
\hline & 2 & 3 & 0.9140 & 95.74 & 95.77 & 133 & 66 \\
\hline \multirow[t]{3}{*}{$\min . \mathrm{O}_{2}$} & 1 & 2 & 0.0562 & 90.22 & 88.00 & 73 & 133 \\
\hline & 1 & 3 & 0.3616 & 90.22 & 91.11 & 73 & 66 \\
\hline & 2 & 3 & 0.0083 & 88.00 & 91.11 & 133 & 66 \\
\hline \multirow[t]{3}{*}{ avg. p.r. (bpm) } & 1 & 2 & 0.0075 & 80.98 & 86.41 & 73 & 133 \\
\hline & 1 & 3 & 0.0007 & 80.98 & 89.50 & 73 & 66 \\
\hline & 2 & 3 & 0.1646 & 86.41 & 89.50 & 133 & 66 \\
\hline \multirow[t]{3}{*}{ low p.r. (bpm) } & 1 & 2 & 0.6247 & 60.36 & 61.33 & 73 & 133 \\
\hline & 1 & 3 & 0.0775 & 60.36 & 64.53 & 73 & 66 \\
\hline & 2 & 3 & 0.1512 & 61.33 & 64.53 & 133 & 66 \\
\hline \multirow[t]{3}{*}{$\%$ of swallowing time when saturation < $95 \%$} & 1 & 2 & 0.0374 & 17.21 & 26.43 & 73 & 133 \\
\hline & 1 & 3 & 0.7804 & 17.21 & 16.09 & 73 & 66 \\
\hline & 2 & 3 & 0.0215 & 26.43 & 16.09 & 133 & 66 \\
\hline
\end{tabular}

Examination 1 - before surgery, examination 2-2 weeks post-surgically, examination 3-4 weeks post-surgically; basal $\mathrm{O}_{2}-$ basal peripheral blond saturation min. $\mathrm{O}_{2}$ - minimal peripheral blood saturation; avg. p.r. - average number of pulse beats per min; low. p.r. - lowest number of pulse beats per min; \% of time $\mathrm{O}_{2}<95 \%$ - time percentage when saturation is lower than $95 \%$; N - number of patients in study group; $\mathrm{p}$ - level of statistic significance of differences

Table 3. Chosen swallowing disturbances in patients after oral cavity neoplasm excision diagnosed in a video fluoroscopic examination

\begin{tabular}{|l|c|c|}
\hline $\begin{array}{l}\text { Features of disturbed } \\
\text { swallowing act }\end{array}$ & $\begin{array}{r}\text { Examination 2: } \\
2 \text { weeks post- } \\
\text { surgically }\end{array}$ & $\begin{array}{c}\text { Examination 3: } \\
4 \text { weeks post- } \\
\text { surgically }\end{array}$ \\
\hline $\begin{array}{l}\text { Oral cavity outflow } \\
\text { Post-deglutition retention }\end{array}$ & $38-28 \%$ & $11-17 \%$ \\
$\begin{array}{l}\text { Leakage into laryngeal } \\
\text { vestibule }\end{array}$ & $26-20 \%$ & $28-43 \%$ \\
Aspiration & $10-8 \%$ & $12-18 \%$ \\
Number of patients & 133 & $7-11 \%$ \\
\hline
\end{tabular}

* the number of patients representing a feature.

\section{Disturbed swallowing features vs saturation}

In examination 3 , oral cavity outflow, post-deglutition retention in the lower pharynx, leakage into the laryngeal vestibule and aspiration were present in fewer patients, but the frequency of disturbances (except the leakage into the laryngeal vestibule) was higher. The aforementioned features of the disturbed swallowing act were juxtaposed with the measurements of its saturation (Table 4). Postdeglutition retention was accompanied with statistically significant saturation in terms of basal saturation, minimal saturation, and lasting time percentage of peripheral blood saturation which was lower than 95\%. Outflow from the oral cavity and leakage into the laryngeal vestibule were accompanied by statistically significant per- centage of lasting time of peripheral blood saturation lower than $95 \%$.

Time percentage of saturation lower than $95 \%$ was the most differentiating value of peripheral blood saturation during swallowing in patients with outflow from the oral cavity, leakage into the laryngeal vestibule, and post-deglutition retention, from the patients in whom the aforementioned disturbances were not present.

\section{Nutrition of patients' choice or recommended by the doctors}

Before 2 weeks passed after the surgery, 23 patients were able to start oral nutrition with a liquid diet. These patients belonged to group 2 due to the range of surgery (their tumor was excised along with the lateral part of the tongue, floor of mouth, and a segment of mandible of full thickness); in all of these cases the continuity of mandibular arch was reconstructed in one stage with neoplasm excision.

Two weeks after surgery and a video fluoroscopic examination, 67 patients started oral nutrition, and 66 of the patients were further subjected to the nasogastric tube feeding and then swallowing rehabilitation was applied to them. Four weeks after surgery and video fluoroscopic examination, another 39 of the patients started oral nutrition. Feeding through the nasogastric tube or temporary gastrostomy with further swallowing rehabilitation were suggested in 27 of the patients.

Saturation values of patients who were able to return to oral nutrition were compared with the adequate values of 
Table 4. Disturbed features of swallowing act vs. chosen values of saturation in examination performed 4 weeks post-surgically

\begin{tabular}{|c|c|c|c|c|c|c|c|}
\hline \multirow{2}{*}{$\begin{array}{l}\text { Disturbed } \\
\text { swallowing features }\end{array}$} & \multirow{2}{*}{$\begin{array}{l}\text { The number } \\
\text { of patients }\end{array}$} & \multicolumn{6}{|c|}{ Chosen values of saturation } \\
\hline & & basal $\mathrm{O}_{2}$ & $\mathrm{p}$ & $\min . \mathrm{O}_{2}$ & $p$ & $\begin{array}{c}\% \text { of time with } \\
\text { sat. }<95 \%\end{array}$ & $p$ \\
\hline \multirow[t]{2}{*}{ Outflow } & yes 11 & 95.02 & \multirow[t]{2}{*}{0.1002} & 89.64 & \multirow[t]{2}{*}{0.1172} & 32.48 & \multirow[t]{2}{*}{0.0029} \\
\hline & no 55 & 95.92 & & 91.44 & & 12.75 & \\
\hline \multirow[t]{2}{*}{ Retention } & yes 28 & 94.49 & \multirow[t]{2}{*}{0.0000} & 88.46 & \multirow[t]{2}{*}{0.0000} & 33.30 & \multirow[t]{2}{*}{0.0000} \\
\hline & no 38 & 96.72 & & 93.07 & & 13.06 & \\
\hline \multirow[t]{2}{*}{ Leakage } & \multirow{2}{*}{$\begin{array}{l}\text { yes } 12 \\
\text { no } 54\end{array}$} & \multirow{2}{*}{$\begin{array}{l}95.15 \\
95.90\end{array}$} & \multirow[t]{2}{*}{0.1878} & 90.09 & \multirow[t]{2}{*}{0.3367} & 27.45 & \multirow[t]{2}{*}{0.0072} \\
\hline & & & & 91.32 & & 13.77 & \\
\hline \multirow[t]{2}{*}{ Aspiration } & yes 7 & 95.75 & \multirow[t]{2}{*}{0.5493} & 91.10 & \multirow[t]{2}{*}{0.9101} & 11.50 & \multirow[t]{2}{*}{0.8792} \\
\hline & no 59 & 96.60 & & 91.50 & & 16.23 & \\
\hline
\end{tabular}

$\mathrm{p}$ - the level of statistically significant differences.

patients who needed nutrition through nasogastric tube or gastrostomy. Saturation time lower than $95 \%$ was reported in patients who, according to a video fluoroscopic examination of swallowing assessment, were able to return to oral nutrition, and a higher percentage of lasting time of peripheral blood saturation which was lower than $95 \%$, was reported in patients who needed to be fed through a nasogastric tube or gastrostomy. The difference was clear in examination 2 and highly statistically significant in examination 3. Table 5 includes the comparison of time percentage of saturation lower than $95 \%$ during swallowing in particular examinations and suggested way of nutrition on the basis of video fluoroscopic examination complemented by pulse oximetry.

We complied the range of surgery, time percentage of saturation lower than $95 \%$ in examination 3, and the recommended method of nutrition. Minimum differences between the compared time percentages of saturation lower than $95 \%$ in patients with maintained nasogastric tube and patients who were able to start oral nutrition amounted to $6.1 \%$ in the group 3 (after resection of half of mandible and the tongue); the greatest differences of $30.35 \%$ were recorded in the group 7 (after the resection of mandibular ramus, lateral wall of pharynx and a part of root of the tongue). Statistically significant differences of the compared values concerned group 2 (the excised lat- eral part of the tongue, floor of the mouth, and mandible), where the level of statistical significance was $\mathrm{p}=0.0015$, and group 7 (excised ramus of mandible, lateral part of the pharynx, and a part of root of the tongue), where the level of statistical significance was $p=0.0002$. Fig. 1 shows the comparison of percentage of lasting time of saturation to be lower than $95 \%$ in patients who were fed naturally and in patients with a maintained nasogastric tube, considering the range of surgery; groups 3, 4 and 5 (the range of surgery concerned more than a half of the tongue) were joined into one group to facilitate the compilation.

Additionally, we performed a comparison of distribution of dependent variables with the KolmogorovSmirnov test for outflow, retention and leakage. ROC curves analysis was performed for the variables which in the Kolmogorov-Smirnov test were significant to achieve the cut-off point which differentiates the distributions the best. The best cut-off ( $\geq 12.2 \%$ ) was chosen for the maximum value of the defined difference on the basis of ROC curves; sensitivity array was $82 \%$, and specificity array was $70 \%$. For the percentage of lasting time of measurements equal or higher than $12.2 \%$, sensitivity array of retention was $82 \%$, i.e. in $82 \%$ of patients with retention lasting time of saturation lower than $95 \%$ was equal or greater than $12.2 \%$, and only $30 \%$ of patients without retention showed such time.

Table 5. Time percentage of saturation lower than 95\% during swallowing vs. recommended way of nutrition in patients after oral cavity neoplasm excision

\begin{tabular}{|c|c|c|c|c|}
\hline Examination & The way of nutrition & The number of patients & $\begin{array}{c}\text { Mean time percentage } \\
\text { of saturation }<95 \%\end{array}$ & $\begin{array}{c}\text { Statistical significance } \\
\text { of differences }\end{array}$ \\
\hline 1 & oral & 73 & 16.84 & \\
\hline \multirow[t]{2}{*}{2} & planned oral & 87 (out of 133) & 22.78 & \multirow[t]{2}{*}{$0.0836^{*}$} \\
\hline & feeding tube maintained & 46 (out of 133) & 33.24 & \\
\hline \multirow[t]{2}{*}{3} & planned oral & 39 (out of 66) & 11.97 & \multirow[t]{2}{*}{0.0000} \\
\hline & feeding tube maintained & 27 (out of 66 ) & 26.12 & \\
\hline
\end{tabular}

* in comparison to the results of patients who took part in both examinations. 


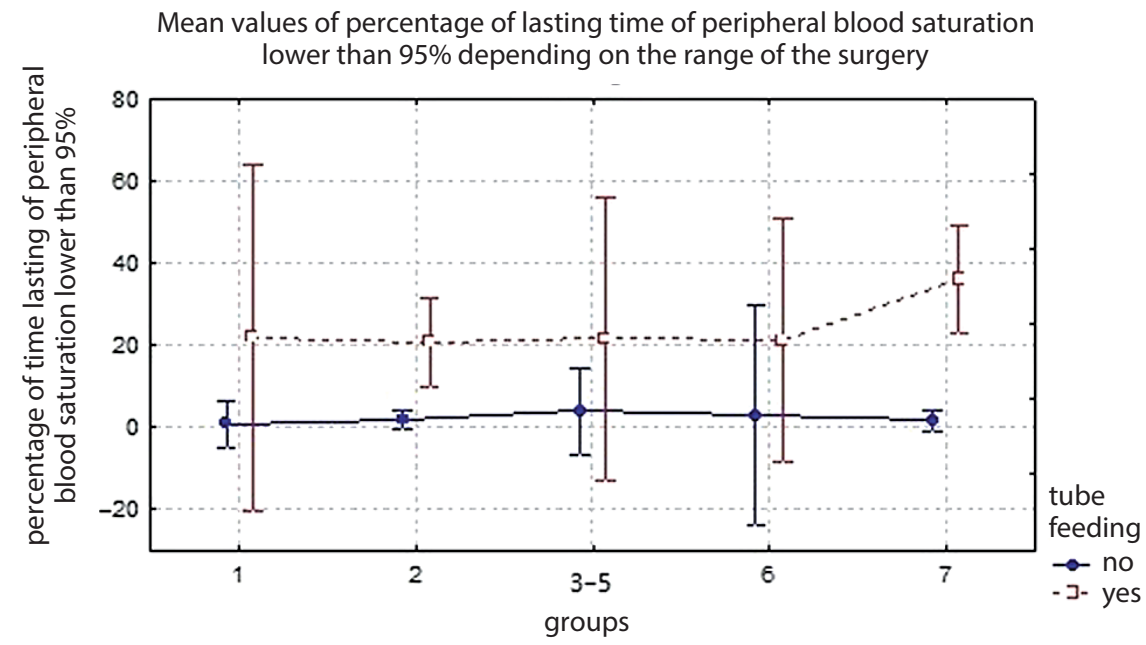

Fig. 1. The necessity for nasogastric tube feeding and the possibility of oral nutrition vs time percentage of saturation lower than 95\% in patients after oral cavity neoplasm excision concerning the range of tissues excision

\section{Discussion}

The role of pulse oximetry in diagnostics of swallowing disturbances is highly valued, especially in bedridden patients. $^{9-11}$ A decrease in the peripheral blood saturation during swallowing, known as the aspiration index, is not only highly appreciated in diagnosing and treating swallowing disturbances, but also significant in aspiration diagnosis. ${ }^{10,12,13}$ The significance of desaturation in aspiration recognition in patients with swallowing disturbances after cerebrovascular accidents and nasopharyngeal cancer postradiation was assessed by Wang, after performing statistical anylysis which did not show to be a test of high sensitivity (58.3\%), nor specificity $(66.7 \%) .{ }^{14}$ However, Collins et al. reported that a decrease in saturation stands for a sensitive array for aspiration in patients after a stroke, therefore, the decrease in saturation was present in $81 \%$ of the patients with aspiration..$^{15}$ The authors emphasize the need for careful interpretation of pulse oximetry results in elderly patients, smokers, or patients affected by chronic lung diseases.

Lack of time synchronization between the activities of oral and pharyngeal swallowing phase, which is present after oral cavity neoplasm excision, is one of the causes of swallowing disturbances. Long-lasting apnea, which begins long before the swallowing trial and lasts even several seconds, is an aspiration that prevents auto-regulatory mechanism applied by the majority of patients. It is accompanied by desaturation, which may be assumed to be an aspiration sensitive array (especially important in cases of 'silent aspiration'), and it is present in the patients who expect to aspirate. ${ }^{7,12,16,17}$

In our study group of patients after oral cavity neoplasm excision, aspiration was not accompanied by the lowest value of peripheral blood saturation during swallowing. The measurements show post-surgical time-dependent variability of the peripheral blood saturation in the patients with oral cavity neoplasm, a significant decrease in the saturation after neoplasm excision, and improvement after 2 weeks of swallowing rehabilitation. The value which changed the least was basal peripheral blood saturation; its fluctuations were less than $3 \%$. The value which changed more (increasing) was the pulse rate; differences between the mean pulse rate in examination 1 and 2 was almost 6 beats per minute, and between examination 2 and 3 it was more than 3 beats per minute. The differences between the mean peripheral blood saturation which was decreased, in examination 1 and 2 during swallowing exceeded $2 \%$, and in examination 2 and 3 they exceeded $1 \%$. The mean percentage of lasting time of saturation lower than $95 \%$ decreased of more than $10 \%$ during swallowing rehabilitation, and it was increased of $9 \%$ after the surgery.

Higher values of minimal saturation, lower percentage of lasting time of saturation lower than $95 \%$, and accompanying pulse rate acceleration were recorded in the examination 4 weeks post-surgically. Certainly, the saturation increase is associated with an improvement of a patient's general condition, but also with putting their swallowing act in order of its course. Video fluoroscopic examination of swallowing plays a key role in enabling the physician and the patient to assess the threat of aspiration, the best position to lower the aspiration risk, and the time of essential mid-swallowing apnea. Providing the patient with a recording of their swallowing act course enables us to determine the moment of apnea and first after-swallow breathe-in with the patient. Deliberate and conscious breathing prevention during swallowing, which lasts long enough to push the bolus into the esophagus but no longer than it is needed, shortened the time of peripheral blood saturation lower than 95\%.

Reports on the unfavorable influence of the activities which improve the inefficient swallowing on the circulatory system (e.g. elongated apnea) called for some additional caution as far as their application in the elderly patients and in patients with heart and vessels diseases is considered. . $^{1,4,16,17}$ The possibility of saliva aspiration as 
well as 'silent saliva aspiration' reported by Takahashi in the elderly patients discourages from creating a situation in which a patient makes decision on how to swallow on his/her own, especially when there may be other diseases co-existing with the oral cavity neoplasm which may complicate swallowing rehabilitation if the rehabilitation is not monitored. ${ }^{18}$ The results of Colodny's research show different general diseases as the cause of desaturation, and negate the advanced age importance in low peripheral blood saturation. ${ }^{1,12}$ Morton et al. finding, based on their research performed in patients with neurologically conditioned oral phase disturbances, that there is a need for research on the influence of breathing control improvement on aspiration reduction in the patients makes the relationship between saturation and oral nutrition possibility worth considering. ${ }^{19}$

Despite the fact that our patients were not diagnosed nor treated due to any cardiovascular system disease, the need for determination of saturation and pulse rate changing during swallowing is justified. Saturation decrease of $62 \%$, pulse rate acceleration to 128 beats per minute, and saturation lower than $95 \%$ and lasting for over $50 \%$ of examination time recorded during swallowing are the unfavorable conditions for oral nutrition. The aforementioned conditions support the idea of changing the current compensatory maneuvers which make the swallowing more efficient, as well as performing the video fluoroscopic examination of swallowing once again.

Pulse oximetry as a complementing method for the video fluoroscopic examination of swallowing in patients after oral cavity neoplasm excision yielded more information to the examination in our patients. Pulse oximetry showed decreased peripheral blood saturation and increased pulse rate in the examination performed 2 weeks post-surgically in comparison with the pre-surgical examination, and the lack of statistically significant correlation between the decrease in peripheral blood saturation and aspiration. The examination enabled us to emerge 3 features of disturbed swallowing in the examination performed 4 weeks post-surgically; post-deglutition retention, leakage into the laryngeal vestibule, and oral cavity outflow were accompanied by significant saturation decrease. The feature which had the greatest correlation with desaturation was post-deglutition retention accompanied by the highest percentage of lasting time of saturation lower than $95 \%$.

Shortening the time of saturation lower than $95 \%$ during swallowing after oral cavity neoplasm excision was only possible thanks to achieving full understanding of the patients swallowing act recording, as well as teaching patients when to hold breath and perform the first breathin after swallowing.
Systematic recording and an analysis of the swallowing acts disturbances in patients after excising the advanced oral cavity neoplasm and accompanying changes in peripheral blood saturation will facilitate monitoring of swallowing rehabilitation.

\section{References}

1. Colodny N. Effects of age, gender, disease, and multisystem involvement on oxygen saturation levels in dysphagic persons. Dysphagia 2001;16:48-57.

2. Hirst LJ, Ford GA, Gibson GJ, Wilson JA. Swallow - induced alterations in breathing in normal older people. Dysphagia 2002;17;152161.

3. Hiss SG, Strauss M, Treole K, Stuart A, Boutilier S. Swallowing apnea as a function of airway closure. Dysphagia 2003;18:293-300.

4. Hiss SG, Treole K, Stuart A. Effects of age, gender, bolus volume, and trial on swallowing apnea duration and swallow respiratory phase relationships of normal adults. Dysphagia 2001;16:128-135.

5. Palmer JB, Hiiemae K. Eating and breathing: Interactions between respiration and feeding on solid food. Dysphagia 2003;18:169-178.

6. Schliephake H, Maximilian UJ. Impact of intraoral soft tissue reconstruction on the development of quality of life after ablative surgery in patients with oral cancer. Plast Reconstr Surg. 2002;109:421430.

7. Dodds WJ, Stewart ET, Logemann JA. Physiology and radiology of the normal oral and pharyngeal phases of swallowing. AJR Am J Roentgenol. 1990;154:953-963.

8. Dodds WJ, Logemann JA, Stewart ET. Radiologic assessment of abnormal oral and pharyngeal phases of swallowing. AJR Am J Roentgenol. 1990;154:965-974.

9. da Freitas Cardoso MC, Toniolo da Silva AM. Pulse oximetry: Instrumental alternative in the clinical evaluation by the bed for the dysphagia. Int Arch Otorhinolaryngol. 2010;14:692-699.

10. Ramsey DJC, Smithard DG, Kalra L. Can pulse oximetry or a bedside swallowing assessment be used to detect aspiration after stroke? Stroke 2006;37:2984-2988.

11. Sherman B, Nisenboum JM, Jesberger BL, Morrow CA, Jesberger JA. Assessment of dysphagia with the use of pulse oximetry. Dysphagia 1999;14:152-156.

12. Colodny N. Comparison of dysphagic and nondysphagic on pulse oximetry during oral feeding. Dysphagia 2000;15:68-73.

13. Leder SB. Use of arterial oxygen saturation, heart rate, and blood pressure as indirect objective physiologic markers to predict aspiration. Dysphagia 2000;15:201-205.

14. Wang TG, Chang YC, Chen SY. Pulse oximetry does not reliably detect aspiration on video fluoroscopic swallowing study. Arch Phys Med Rehabil. 2005;86:730-734.

15. Collins MJ, Bakheit AM. Does pulse oximetry reliable detect aspiration in dysphagic stroke patients? Stroke 1997;28:1773-1775.

16. Rogers B, Msall M, Shucard D. Hypoxemia during oral feedings in adults with dysphagia and severe neurological disabilities. Dysphagia 1993;8:43-48.

17. Dharmarajan TS, Unnikkrishnan D. Tube feeding in the elderly. Postgrad Med. 2004;115:51-61.

18. Takahashi N, Kikutani T, Tamura T, Groher M, Kuboki T. Videoendoscopic assessment of swallowing function to predict the future incidence of pneumonia of the elderly. J Oral Rehabil. 2012; 39:429-437.

19. Morton R, Minford J, Ellis R, Pinington L. Aspiration with dysphagia: The interaction between oropharyngeal and respiratory impairment. Dysphagia 2002;17:192-196. 